\title{
Influence of Calcium Supplements for the Biomimetic Apatite Formation on Titanium Implants-An in vitro study
}

\author{
Suja Mathai* \\ Assistant Professor, Department of Chemistry, Mar Ivanios College (Autonomous), Thiruvananthapuram, Kerala, India \\ *Address for Correspondence: Dr. Suja Mathai, Professor, PG and Research Department of Chemistry, Mar Ivanios \\ College (Autonomous), Thiruvananthapuram-695015, Kerala \\ E-mail: sujamathaikunnath@gmail.com
}

Received: 26 Apr 2021/ Revised: 23 June 2021/ Accepted: 03 Aug 2021

\begin{abstract}
Background: Osteoporosis, the most frequent metabolic disease of the bone, represents an important cause of morbidity in the elderly. The major clinical manifestations of osteoporosis, diffuse disease of the skeleton, consists of fractures of the vertebral, of the limbs and the femoral neck. In this situation, the calcium supplements available in markets may help to meet our calcium requirements.

Methods: The alkaline-treated Ti samples were soaked in $24 \mathrm{ml}$ of SBF and SBF modified with calcium supplements available in markets like- calcium lactate, calcium nitrate, calcium acetate, calcium carbonate respectively for 20 days. The influence of calcium supplements was evaluated by the apatite-forming ability in a simulated body fluid (SBF) by various characterization and evaluation techniques and found out the best calcium supplement that can be better absorbed during apatite formation.

Results: An increased apatite forming ability for the $\mathrm{NaOH}$-heat treated $\mathrm{Ti}$ after immersion in SBF modified with calcium supplements than $\mathrm{NaOH}$ and heat-treated Ti, was confirmed by the Scanning Electron Microscope (SEM), Energy Dispersive X-ray (EDX), the X-Ray Diffraction (XRD), and the Fourier Transform Infrared Spectrometer (FTIR) analysis.

Conclusion: Calcium gluconate, calcium nitrate, and calcium carbonate are likely to be the most effective calcium supplements for osteoporosis prevention. Thus, even in the living organism, the treated $\mathrm{Ti}$ is predicted to produce bone-like apatite on its surface and connect to live bone.
\end{abstract}

Key-words: Alkaline-treated, Bone-like apatite, Calcium supplements, Modified SBF, Osteoporosis, Simulated body fluid

\section{INTRODUCTION}

Titanium (Ti) is often regarded as the best metal for in vivo applications, because of its exceptional bio compatibility ${ }^{[1]}$. Despite their high biocompatibility, titanium implants seldom create a direct chemical connection with bone tissue and are frequently referred to be inert material ${ }^{[2,3]}$. Hydroxyapatite also known as $\mathrm{Ca}_{10}\left(\mathrm{PO}_{4}\right)_{6} /(\mathrm{OH})_{2}$ is a biocompatible ceramic substance, can create a strong chemical connection with natural bone tissue ${ }^{[4,5]}$ and may be utilized to cover metallic implants ${ }^{[6]}$. One of the potential implant materials for orthopaedic purposes is HA-coated Ti metal ${ }^{[7]}$.

\section{How to cite this article}

Mathai S. Influence of Calcium Supplements for the Biomimetic Apatite Formation on Titanium Implants-An in vitro study. SSR Inst. Int. J. Life Sci., 2021; 7(5): 2860-2866.

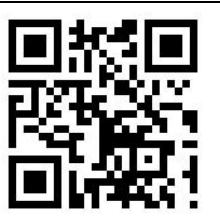

The implant's underlying metal is ductile, and the bioactive surface encourages bone growth and improves implant-bone adhesion ${ }^{[8]}$.

Coating HA onto metallic substrates has been done using a variety of methods; including physical vapour deposition, chemical vapour deposition, plasma spray, and laser deposition ${ }^{[9]}$. All of these methods have the drawback of being high-temperature procedures that result in the production of readily dissolvable calcium phosphate (CaP) phases such as amorphous $H A$, $\mathrm{Ca}_{3}\left(\mathrm{PO}_{4}\right)_{2}$, and $\mathrm{Ca}_{4} \mathrm{P}_{2} \mathrm{O}_{9}{ }^{[10,11]}$. Furthermore, these methods were unable to produce high crystallinity HA coatings, which are necessary for optimal biocompatibility.

The biomimetic deposition is a low-temperature method for generating bioactive $\mathrm{CaP}$ coatings on porous and nonporous surfaces ${ }^{[12-15]}$. The best technique to generate man-sized apatite crystals with regulated size on the surface of $\mathrm{Ti}$ is to use a biomimetic approach that entails generating nucleation sites on the metal surface by 
modifying its surface with functional groups and then mineralization in simulated bodily fluids (SBF) ${ }^{[16]}$. However, to achieve excellent biomimetic apatite deposition, two requirements must be met: (1) supersaturation of calcium and phosphate ions in the solution ${ }^{[17-21]}$ and (2) activation of the Ti surface ${ }^{[22,23]}$.

Children need calcium to build strong bones. Adults need calcium to maintain strong bones. Over time, inadequate calcium intake can cause osteoporosis, the brittle bone disease. People with osteoporosis are at high risk for broken bones, especially at the wrist, hip and spine. These fractures cause chronic pain and disability, loss of independence, decreased quality of life and a higher risk of death. In this study, commercially available calcium supplements were used, and their impact on biomimetic apatite development on titanium implants was investigated using an in vitro biomimetic technique, resulting in the identification of the optimum calcium supplement for improved absorption.

\section{MATERIALS AND METHODS}

Pre-treatment of Ti sample- Commercially pure Ti (CP-Ti), (Sigma Aldrich) of surface area $(20 \times 20 \times 1 \mathrm{~mm} 3)$ was used. Each $\mathrm{Ti}$ metal sample was mechanically grounded with 60 grit sandpaper to achieve a mirror-finished surface. Subsequently, the samples were cleaned with ethanol, distilled water and dried. The samples were alkaline treated for 24 hours at $60^{\circ} \mathrm{C}$ with a $5 \mathrm{M} \mathrm{NaOH}$ aqueous solution. The samples were gently washed with ultrapure water before being dried at 40 o degrees Celsius. They were then heated to $600^{\circ} \mathrm{C}$ at a rate of $50^{\circ} \mathrm{C} / \mathrm{min}$ for 1 hour and then cooled naturally in an electrical furnace [24].

Evaluation of the bioactivity of the alkaline-treated $\mathrm{Ti}$ sample by surface potential measurement- The apatiteforming ability in simulated bodily fluid (SBF) proposed by Fer et al. ${ }^{[25]}$ with ion concentrations approximately comparable to those of human blood plasma, was used to assess the bioactivity. The alkaline-treated Ti samples were soaked in $24 \mathrm{ml}$ of SBF at $36.5^{\circ} \mathrm{C}$. Another set of samples were immersed in modified SBF solution by adding $10 \mathrm{mg}$ of a calcium supplement like calcium gluconate to $100 \mathrm{~mL}$ of the solution. The same was repeated for another set of alkaline treated Ti samples for other calcium supplements like- calcium lactate, calcium nitrate, calcium acetate, calcium carbonate respectively. The samples were removed after soaking in
SBF and modified SBF for 20 days, washed with ultrapure water, and dried at $40^{\circ} \mathrm{C}$.

\section{Evaluation of the bioactivity of the alkaline-treated $\mathrm{Ti}$} sample by chemical evaluation techniques- The surface potential change of the alkaline treated substrates in modified SBF solutions were carried out using by measuring the open circuit potential (OCP). FTIR analyses of the samples after the biomimetic study were carried out to find the apatite growth. A few micrograms of the coatings were scraped off and mixed with $\mathrm{KBr}$ and pressed into pellets for FTIR analysis using Shimadzu FTIR spectrophotometer, Model: IR Prestige-21. An X-ray diffractometer, model: X-Pert Pro was used to examine the phases and crystallinity of the samples. CuK radiation at40 kV and $30 \mathrm{~mA}$ were utilized as the $X$-ray source in the XRD experiments and the samples were scanned from $10-70^{\circ} 2 \theta$ at a scan rate of $1.2^{\circ} / \mathrm{min}$. The crystalline size of the particles DXRD was calculated according to the Scherer equation:

\section{$D_{X R D}=0.9 \lambda / B \cos \theta$}

Where,

$\lambda$ - The wavelength of the radiation

$\theta$ - The diffraction angle

B- The corrected half-width of the diffraction peak ${ }^{[26-28]}$

Evaluation of the bioactivity of the alkaline-treated $\mathrm{Ti}$ sample by surface morphological analysis- The surfaces of the samples subjected to the chemical, heat treatments and soaked in modified SBF were analyzed by field emission scanning electron microscopy (FE-SEM: S4300, Hitachi Co., Tokyo, Japan) equipped with energy dispersive X-ray (EDX: EMAX-7000, HORIBA Ltd., Kyoto, Field emission scanning electron microscopy (FE-SEM: S4300, Hitachi Co., Tokyo, Japan) equipped with energy dispersive X-ray (EDX: EMAX-7000, HORIBA Ltd., Kyoto, Japan) spectroscopy was used to examine the surfaces of the samples that had been subjected to chemical, heat, and modified SBF treatments.

\section{RESULTS}

Fig. 1 shows the change in surface potential of Ti samples following $\mathrm{NaOH}$-heat treatments and 20 days in modified SBF. The surface potential, which was initially highly negative, shifted towards the anodic direction, reached a maximum value within 5 days, and then shifted back to the cathodic direction. 


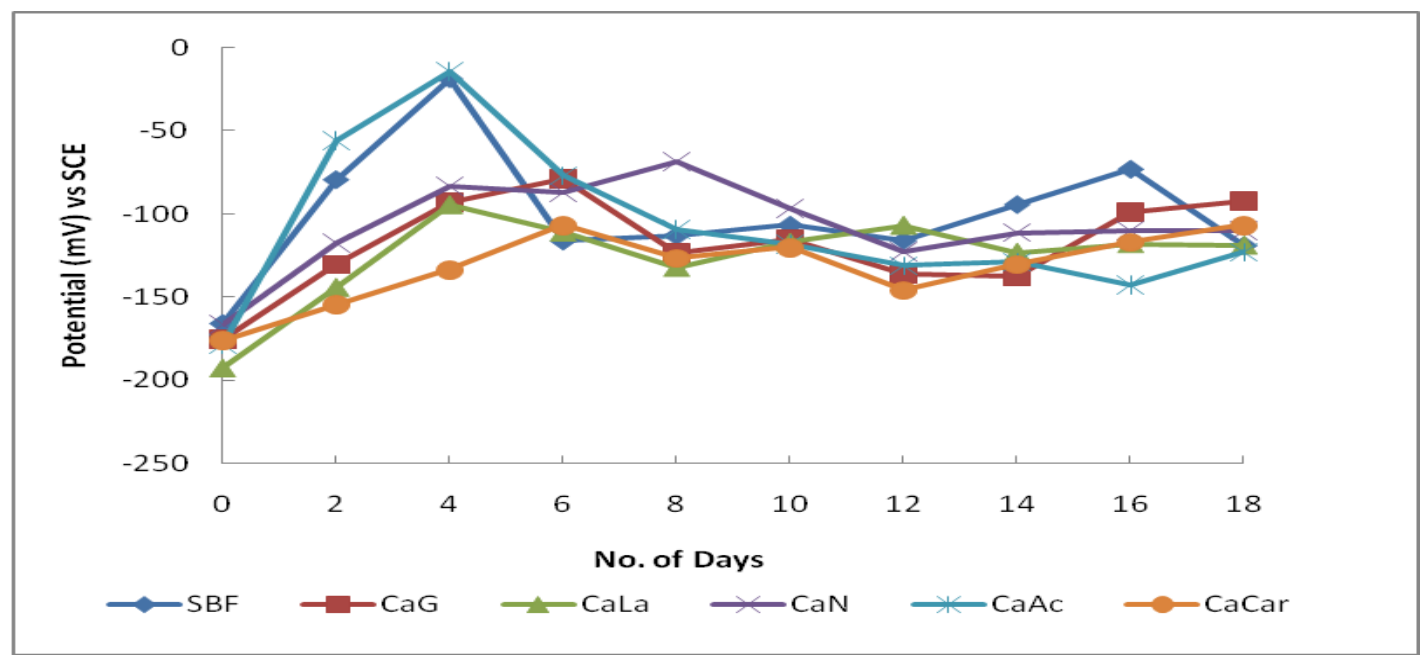

Fig. 1: Surface potential change for the Ti samples after $\mathrm{NaOH}$-heat treatment and soaked in modified SBF for 20 days

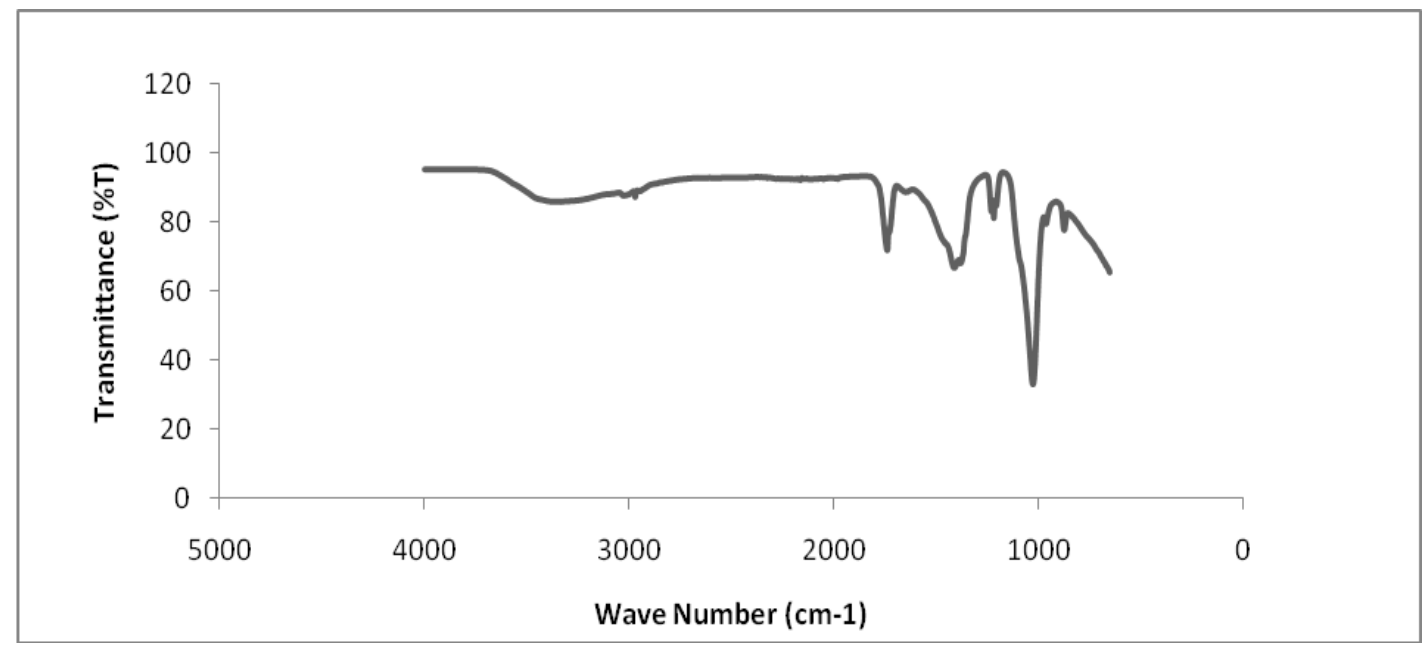

Fig. 2: FTIR spectrum of the Ti samples after $\mathrm{NaOH}$-heat treatment soaked in modified SBF for 20 days

Fig. 2 shows the FTIR spectrum of the Ti samples after $\mathrm{NaOH}$-heat treatments and soaked in modified SBF for 20 days. A spectral region from $4000-5000 \mathrm{~cm}^{-1}$ was analyzed. The frequency corresponding to $3444.74 \mathrm{~cm}^{-1}$ was due to the $\mathrm{OH}$ stretching vibration of the $\mathrm{HA}$ coating. The peaks at $1033 \mathrm{~cm}^{-1}$ correspond to that of $\mathrm{PO}_{4}{ }^{3-}$ and the peak at $879 \mathrm{~cm}^{-1}$ was due to the presence of $\mathrm{HPO}_{4}{ }^{2-}$ ions. The peaks at $1432 \mathrm{~cm}^{-1}$ were due to carbonate ions.

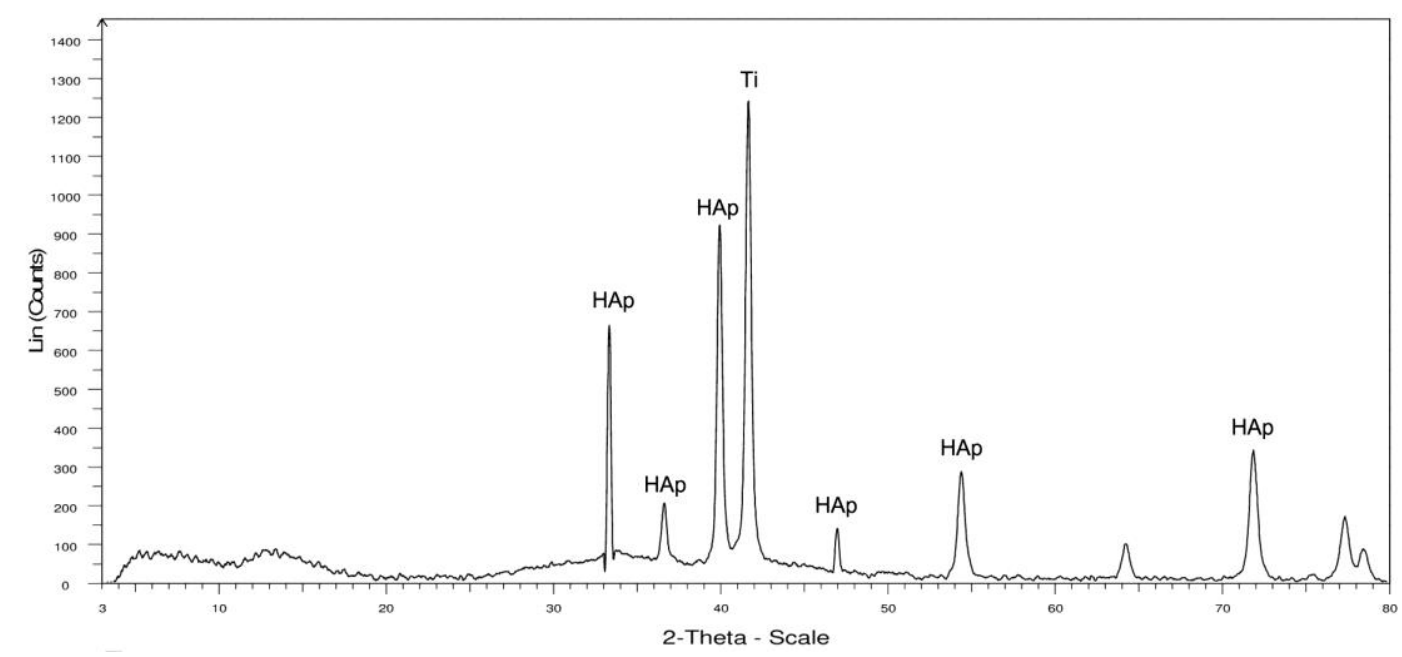

Fig. 3: XRD patterns of the surfaces of $\mathrm{Ti}$ after $\mathrm{NaOH}$-heat treatments and soaked in SBF modified with calcium gluconate 20 days 
XRD patterns of the surfaces of $\mathrm{Ti}$ after (a) $\mathrm{NaOH}$-heat treatments and (b) soaked in modified SBF for 20 days are shown in Fig. 3. The resultant values of $2 \theta$ are compared with the standard cards of JCPDS. XRD results indicate that the diffraction pattern of both the coatings matches with the XRD patterns of the HA of good quality and also with the JCPDS value of pure HA. No X-ray evidence was found for the existence of other $\mathrm{CaP}$ phases in the coatings. The peaks appeared at $2 \theta=25^{\circ}$, $32^{\circ}, 39.2^{\circ}, 46.7^{\circ}, 49.46^{\circ}$ and $53.14^{\circ}$ obtained for both the coatings corresponds to that of crystalline apatite.
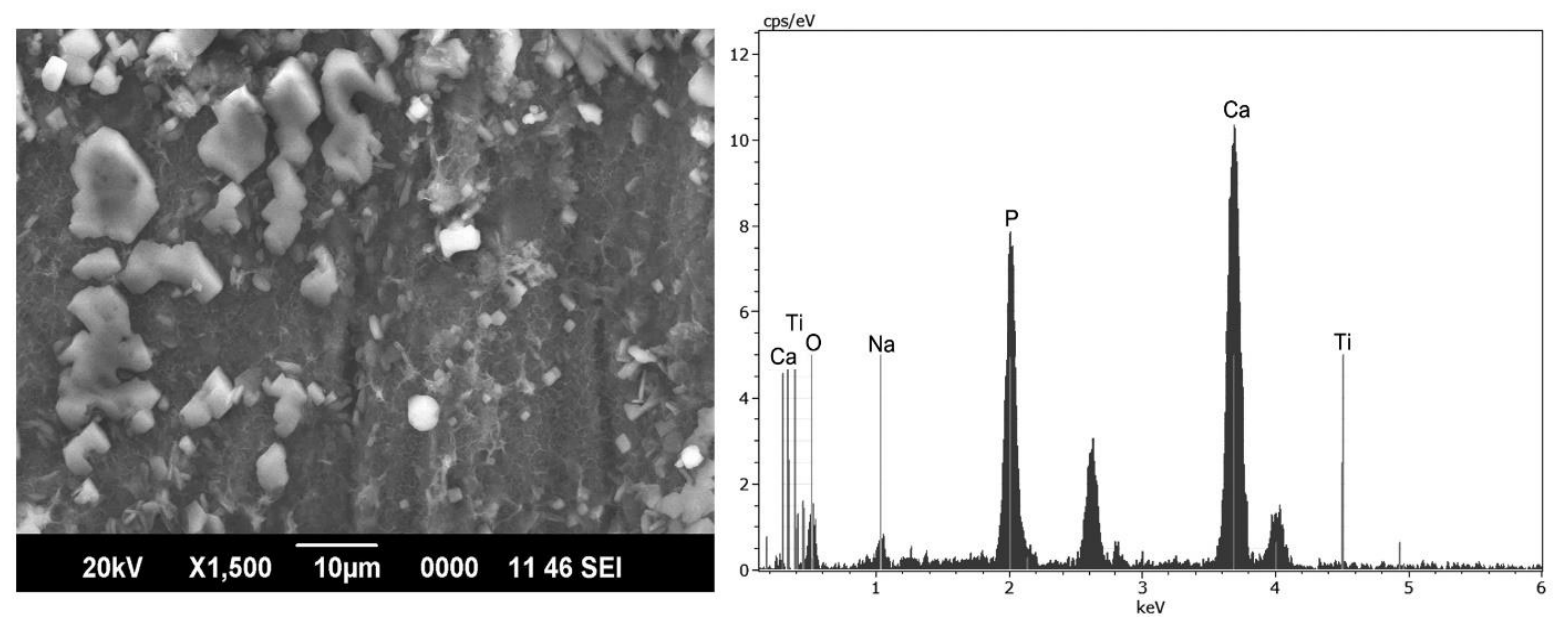

(a)
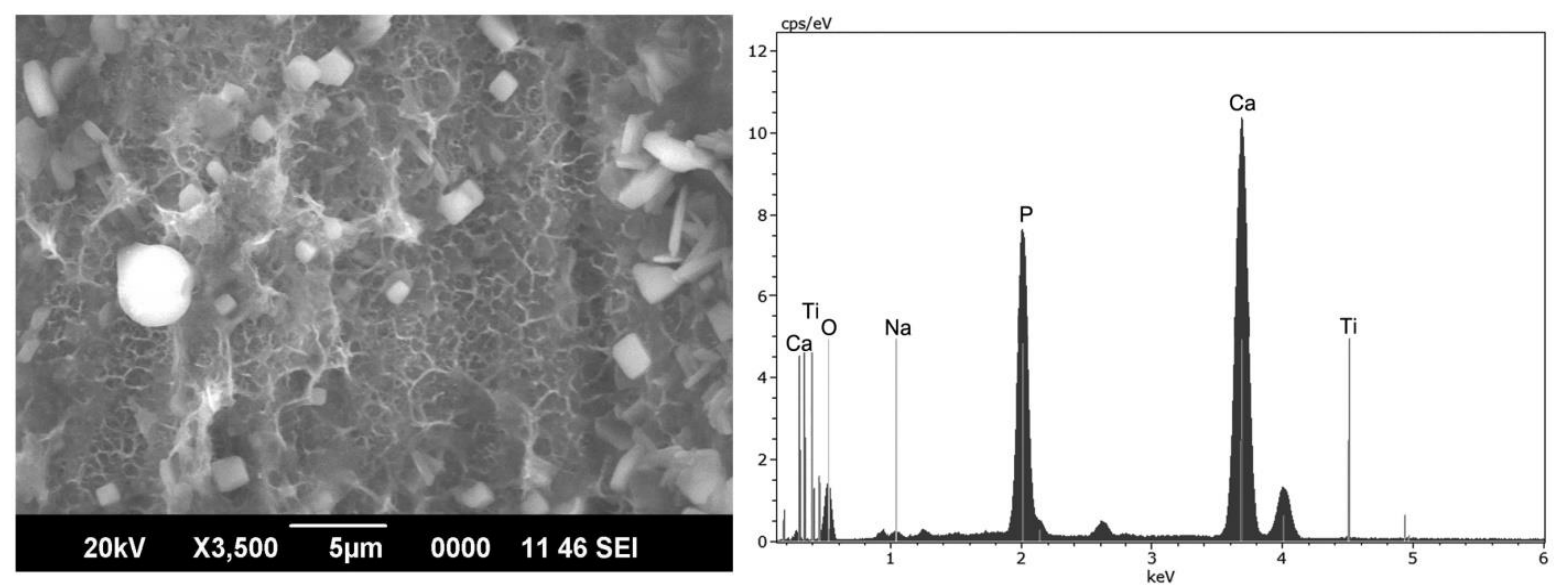

(b)

Fig. 4: SEM and EDX analysis of the surfaces of Ti after $\mathrm{NaOH}$, heat treatments and immersion in SBF modified with (a) calcium gluconate and (b) calcium nitrate for 20 days

Fig. 4 shows that white crystalline precipitates of apatite were found to be more covered on the treated sample immersed in SBF modified with calcium gluconate. White crystalline precipitates of apatite were also found on the surfaces of other samples immersed in SBF modified with calcium lactate, calcium acetate, calcium carbonate. Peaks of varying intensities were also detected depending on the thickness of the film. Sharp peaks obtained for $\mathrm{Ca}$ and $\mathrm{P}$ during EDX analysis confirmed the formation of $\mathrm{CaP}$ phases on the surfaces were also found to have very intensive peaks of $\mathrm{Ca}$ and $\mathrm{P}$ than the SBF modified with calcium nitrate, calcium acetate, calcium lactate.
Moreover, the intensity of the $\mathrm{Ti}$ substrate decreased due to interference from calcium phosphate deposits. Table 1 shows the elemental percentage of $\mathrm{Ca}$ and $\mathrm{P}$ on the surface of the surfaces of $\mathrm{Ti}$ after $\mathrm{NaOH}$, heat treatments and immersion in SBF and modified SBF for 20 days which were analyzed by EDX. The table shows that $\mathrm{NaOH}$-heat treated samples after immersion in modified SBF containing calcium gluconate, calcium nitrate and calcium carbonate, have a significant increase in the amount of $\mathrm{Ca}$ and $\mathrm{P}$ due to the formation of apatite. 
Table 1: Elemental percentage of $\mathrm{Ca}$ and $\mathrm{P}$ on the surface of the surfaces of $\mathrm{Ti}$ after $\mathrm{NaOH}$, heat treatments and immersion in SBF and modified SBF for 20 days

\begin{tabular}{|c|c|c|c|}
\hline Sample & \multicolumn{3}{|c|}{ Elemental (\%) } \\
\hline $\begin{array}{l}\text { NaOH-heat treated } \\
\text { Ti immersed }\end{array}$ & 0 & $\mathbf{P}$ & $\mathrm{Ca}$ \\
\hline SBF & 62.62 & 8.04 & 10.17 \\
\hline \multicolumn{4}{|c|}{ SBF modified with } \\
\hline Calcium gluconate & 65.06 & 20.97 & 22.58 \\
\hline Calcium lactate & 29.49 & 8.47 & 10.58 \\
\hline Calcium nitrate & 61.80 & 12.80 & 20.75 \\
\hline Calcium acetate & 58.28 & 8.58 & 13.06 \\
\hline Calcium carbonate & 48.15 & 13.03 & 13.48 \\
\hline
\end{tabular}

\section{DISCUSSION}

The peak corresponds to that of $\mathrm{PO}_{4}{ }^{3-}, \mathrm{HPO}_{4}{ }^{2-}$ and carbonate ions corresponds to the presence of crystalline apatite ${ }^{[28,29]}$. The peaks appeared at $2 \theta=25^{\circ}$, $32^{\circ}, 39.2^{\circ}, 46.7^{\circ}, 49.46^{\circ}$ and $53.14^{\circ}$ obtained for both the coatings corresponds to that of crystalline apatite ${ }^{[29,30]}$. It has been found that the alkaline treated $\mathrm{Ti}$ forms a sodium titanate $\left(\mathrm{Na}_{2} \mathrm{Ti}_{5} \mathrm{O}_{11}\right)$ surface layer. This sodium titanate could form many $\mathrm{Ti}-\mathrm{OH}$ groups in SBF. The mechanism of apatite formation on $\mathrm{TiO}_{2}$ in $\mathrm{SBF}$ can be interpreted in terms of the electrostatic interaction of the surface oxide with the ions in the fluid. When exposed to $\mathrm{SBF}$, the $\mathrm{Na}^{+}$ions in the surface layer of $\mathrm{Na}_{2} \mathrm{Ti}_{5} \mathrm{O}_{11}$ are exchanged with $\mathrm{H}_{3} \mathrm{O}^{+}$ions present in the fluid facilitating the formation of $\mathrm{Ti}-\mathrm{OH}$ groups. Because of the negatively charged ions at the surface, the initial surface potential during biomimetic development in SBF

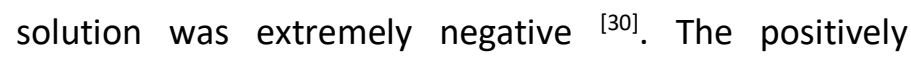
charged calcium $\left(\mathrm{Ca}^{2+}\right)$ ions from the SBF solution are preferentially attracted to this negatively charged surface, and the potential is shifted to the anodic direction. The negatively charged phosphate $\left(\mathrm{HPO}_{4}{ }^{2-}\right)$ ions are attracted to this positively charged surface, forming an amorphous $\mathrm{CaP}$, and the potential shifts are negative. This CaP develops into crystalline apatite on its own. Because the SBF is significantly supersaturated about apatite even under normal circumstances, the apatite develops spontaneously by taking the calcium and phosphate ions in the fluid once created [31,32].
The $\mathrm{NaOH}$ treatment produced spherical precipitates on the Ti surface that were made up of nano-sized sodium hydrogen titanate with a layered structure. The sodium hydrogen titanate in SBF releases its $\mathrm{Na}^{+}$ions by exchanging them with $\mathrm{H}_{3} \mathrm{O}^{+}$ions on its surface, forming $\mathrm{Ti}-\mathrm{OH}$ groups. Thus, the formed $\mathrm{Ti}-\mathrm{OH}$ groups induce apatite formation as earlier described for the $\mathrm{NaOH}$-and heat-treated Ti metal ${ }^{[3,34]}$. The SBF utilized to study the effect of surface charge on the nucleation and development of calcium phosphate phases in vitro was a supersaturated solution containing calcium supplements. From SEM-EDX analysis results, calcium supplements, such as calcium gluconate, calcium nitrates, and calcium carbonate, have been shown to improve apatite formation. It is a component of various calcium supplements for the control of blood calcium levels due to its high re-sorbability. It is non-toxic and has high physiological compatibility.

\section{CONCLUSIONS}

The higher the calcium dose, the less it's absorbed. For maximum absorption, the calcium supplement added in the SBF was optimized. An increased apatite forming ability for the $\mathrm{NaOH}$-heat treated $\mathrm{Ti}$ after immersion in SBF modified with calcium supplements than normal SBF was confirmed by the Scanning Electron Microscope (SEM), Energy Dispersive X-ray (EDX), the X-Ray Diffraction (XRD), and the Fourier Transform Infrared Spectrometer (FTIR) analysis. Thus, even in the living organism, the treated $\mathrm{Ti}$ is predicted to produce bonelike apatite on its surface and connect to live bone. Calcium gluconate, calcium nitrate, and calcium carbonate are likely to be the most effective calcium supplements for osteoporosis prevention.

To promote lifelong healthy bones and reduce calcium loss, it is recommended to intake vitamin $D$ besides calcium supplements throughout your life.

\section{ACKNOWLEDGMENTS}

The author acknowledges the financial support from the Kerala State Council of Science and Technology (KSCSTE), India.

\section{CONTRIBUTION OF AUTHORS}

One author is only contributed in this article. 


\section{REFERENCES}

[1] Cai Z, Shafer TY, Watanabe I, Nunn ME, Okabe T. Electrochemical characterization of cast titanium alloys. Biomat., 2003; 24: 213-18.

[2] Huang LY, Xu KW, Lu J. A study of the process and kinetics of electrochemical deposition and hydrothermal synthesis of hydroxyapatite coating. J Mater Sci Mater Med., 2000; 11: 667-73.

[3] Shirkhanzadeh M. Calcium phosphate coatings prepared by electron crystallisation from aqueous electrolytes. J. Mater Sci Mater Med., 1995; 6: 90-93.

[4] Rivero DP, Fox J, Skipor AK, Urban RM, Galante JO. Calcium phosphate-coated porous titanium implants for enhanced skeletal fixation. J Biomed Mater Res., 1988; 22: 191-201.

[5] Shirkhanzadeh M. Direct formation of nanophase hydroxyapatite coatings prepared by electrodeposition and alkaline-treatment process. J Biomed Mater Res., 1998; 9: 67-72.

[6] Wang CX, Wang $M$, Zhou X. Electrochemical impedance spectroscopy study of the nucleation and growth of apatite on chemically treated titanium. Langmuir., 2002; 18: 7641-47.

[7] Han Y, Fu T, Lu J, Xu K. Characterization and stability of hydroxyapatite coatings prepared by an electrodeposition and alkaline treatment process. J Biomed Mater Res., 2001; 54: 96-101.

[8] Cook SD, Thomas KA, Dalton JE. Hydroxy apatite coating of porous implants improves bone in growth and interface attachment strength. J Biomed Mater Res., 1992; 26: 989-01.

[9] Han Y, Xu K, Lu J. Morphology and composition of hydroxyapatite coatings prepared by hydrothermal treatment of electrodeposited brushite coatings. J Mater Sci Mater Med., 1999; 10: 246-48.

[10]Wang BC, Chang E, Lee TM, Lee CY. Changes in phases and crystallinity of plasma-sprayed hydroxyapatite coatings under heat treatment: Aquantitative study. J Biomed Mater Res., 1995; 29 : 1483-92.

[11]Dalton JE, Cook SD. In vivo mechanical and histological characteristics of hydroxyapatite coated implants vary with coating vendor. J Biomed Mater Res., 1995; 29: 239-45.

[12]Chen MS, Juang $\mathrm{HY}, \mathrm{Hon} \mathrm{MH}$. Calcium phosphate coating on titanium substrate by a modified electrocrystallization process. J Mater Sci Mater Med., 1998; 9: 297-300.

[13] de Assis CM, Vercik O de LC, Santos dos ML, Fook MVL, Guastaldi AC. Comparison of crystallinity between natural hydroxyapatite and synthetic cpTi/HA coatings. Mater Res., 2005; 8: 207-11.

[14]Abe Y, Kokubo T, Yamamuro T. Apatite coating on ceramics, metals and polymers utilizing a biological process. J Mater Sci Mater Med., 1990; 1: 233-38.

[15]Barrere F, Layrolle P, Blitterswijk CAV, de Groot K. Biomimetic calcium phosphate coatings on Ti6Al4V. A crystal growth study of octa calcium phosphate and inhibition by $\mathrm{Mg}^{2+}$ and $\mathrm{HCO}_{3}{ }^{-}$. Bone, 2000; 25 : 137-41.

[16]Robler S, Sewing A, Stolzel M, Born, R, Scharnweber $D$, et al. Electrochemically assisted deposition of thin calcium phosphate coatings at near-physiological $\mathrm{pH}$ and temperature. J Biomed Mater Res., 2002; 64A: 655-63.

[17]Zhang $Q$, Leng $Y$, Electrochemical activation of titanium for biomimetic coating of calcium phosphate. Biomater., 2005; 26: 3853-59.

[18]Kokubo T, Kushitani H, Sakka S, kitsugi T, Yamamuro. Solutions able to reproduce in vivo surface-structure changes in bioactive glass-ceramics A-W-G. J Biomed Mater Res., 1990; 24: 721-34.

[19]Barrere F, Layrolle P, Blitterswijk CAV, de Groot K. Nucleation of biomimetic Ca-P coatings on Ti6Al4V from a SBF $x 5$ solution: influence of magnesium. Biomater., 2002; 23: 2211-20.

[20]Barrere F, Blitterswijk CAV, de Groot K, Layrolle P. Fast formation of biomimetic Ca-P coatings on Ti6Al4V. Mater. Res Soc Symp Proc., 2000; 599: 13540.

[21]Barrere F, Layrolle P, Blitterswijk CAV, de Groot K. Influence of ionic strength on the Ca-P coating formation from SBF x 5 solutions. Biomater., 2002; 23: 1921-30.

[22]Kim HM, Miyaji F, Kokubo T, Nakamura T. Preparation of bioactive $\mathrm{Ti}$ and its alloys via simple chemical surface treatment. J. Biomed Mater Res., 1996; 32: 409-17.

[23]Kokubo T, Miyaji F, Kim HM, Nakamura T. Spontaneous formation of bonelike apatite layers on chemically trated titanium metals. J Am Ceram Soc., 1996; 79: 1127-29. 
[24]Fatehi K, Moztarzadeh F, Solati-Hashjin M, Tahriri M, Rezvannia $M$, Ravarian $R$. In vitro biomimetic deposition of apatite on alkaline and heat treated $\mathrm{Ti}_{6} \mathrm{Al}_{4} \mathrm{~V}$ alloy surface. Bull Mater Sci., 2008; 31(2): 101-08.

[25]Fer YP, Lin $\mathrm{CH}$, Hsu CS. Preparation of ultrafine $\mathrm{CeO}_{2}$ powders by microwave induced combustion and precipitation. J Alloys Compd., 2005; 391: 110-17.

[26] Han Y, Fu T, Lu J, Xu K. Characterization and stability of hydroxyapatite coatings prepared by an electrodeposition and alkaline treatment process. J Biomed Mat Res., 2001; 54: 96-01.

[27]Somasundaran P, Markovic B. Interfacial properties of calcium phosphate, In: Amjad Z, (Ed): Calcium phosphate in biological and industrial system. Tran Tech Pub., 1998; 85-101.

[28]Takadama H, Kim HM, KokuboT, Nakamura T. An Xray photoelectron spectroscopy study of the process of apatite formation on bioactive titanium metal. J Biomed Mater Res., 2001; 55: 185-93.

[29]Dong ZL, Khor KA, Quek CH, White TJ. TEM and STEM analysis on heat-treated and in vitro plasma-sprayed hydroxyapatite/Ti-6Al-4V composite coatings. Biomat., 2003; 24: 97-05.
[30] Kim HM, Himeno T, Kawashita M, Lee JH, Kokubo T, et al. Surface potential change in bioactive titanium metal during the process of apatite formation in simulated body fluid. J Biomed Mater Res., 2003; 67A: 1305-09.

[31]Takadama H, Kim HM, Kokubo T, Nakamura T. TEMEDX study of mechanism of bonelike apatite formation on bioactive titanium metal in simulated body fluid. J Biomed Mater Res., 2001; 57: 441-48.

[32] Kim HM, Miyaji F, Kokubo T, Nakamura T. Apatiteforming ability of alkali-treated $\mathrm{Ti}$ metal in body environment. J Ceram Soc Japan, 1997; 105: 111-16.

[33]Shibli SMA, Suja M. Development and bioelectrochemical characterization of a novel $\mathrm{TiO}_{2}-\mathrm{SiO}_{2}$ mixed oxide coating for titanium implants. J Mater Sci., 2008; 19: 2971-81.

[34]Takadama H, Kim HM, Kokubo T, Nakamura T. An XPS study of the process of apatite formation on bioactive titanium metal in simulated body fluid. J Biomed Mater Res J Biomed Mater Res., 2001; 55: 185-93.

\section{Open Access Policy:}

Authors/Contributors are responsible for originality, contents, correct references, and ethical issues. SSR-IIJLS publishes all articles under Creative Commons Attribution- Non-Commercial 4.0 International License (CC BY-NC). https://creativecommons. org/licenses/by-nc/4.0/legalcode (c) (i) (9) 